\title{
Meeting the family planning and reproductive health needs of factory workers
}

Evidence Project

Follow this and additional works at: https://knowledgecommons.popcouncil.org/departments_sbsr-rh How does access to this work benefit you? Let us know!

\section{Recommended Citation}

Evidence Project. 2021. "Meeting the family planning and reproductive health needs of factory workers," Learnings from the Evidence Project. Washington, DC: Population Council, The Evidence Project. 


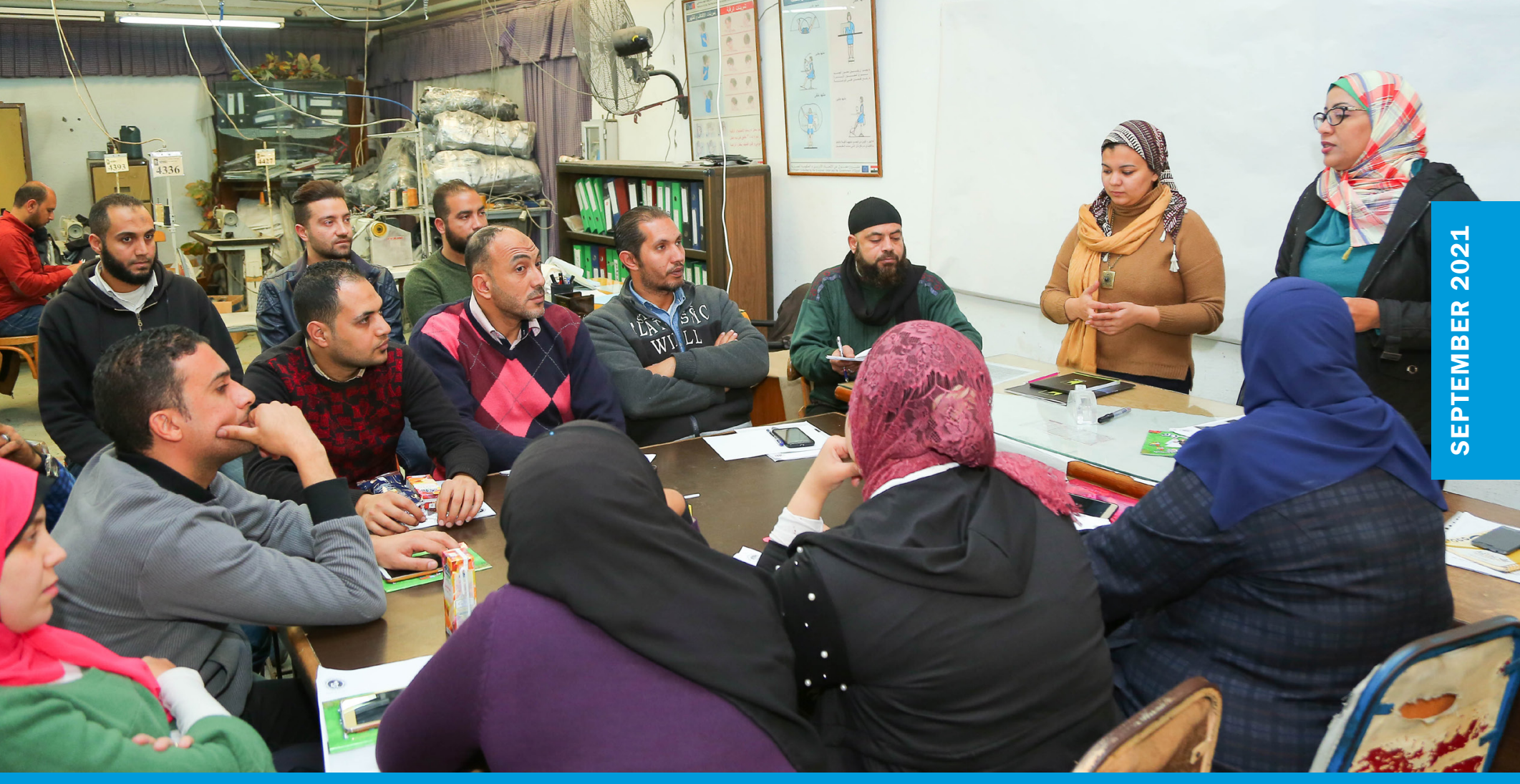

\section{Meeting the Family Planning and Reproductive Health Needs of Factory Workers}

For many people of reproductive age, a significant proportion of their time is spent in the workplace. Women have joined the formal workforce in significant numbers, especially the garment sector, in many low- and middle-income countries. ${ }^{1}$ Factory workers often migrate from rural areas in search of work and have limited access to basic health information and services. ${ }^{1}$ Some companies recognize that the workplace may be an excellent avenue for reaching individuals with health information and services, and that investing in the health and well-being of employees is beneficial to both employees and employers. ${ }^{2-4}$ Yet, workplace health programming, when it exists, has typically focused narrowly on occupational health and safety compliance. ${ }^{5}$ Few studies have been conducted on programs for family planning/ reproductive health (FP/RH) for factory workers. The Evidence Project contributed to improving workers' FP/RH through two sets of activities: (1) advocacy efforts to improve FP/RH practices and global and cor-

\section{KEY LESSONS}

On-site peer education models, especially those augmented by social media and other communication materials, may be valuable ways to address the sexual and reproductive health (SRH) needs of women, men, and young people at work.

Collaboration with factory management can help to support successful implementation and generate interest in sustaining worker health programming.

Beyond providing health education, making health services available on-site can enable employees to overcome barriers to access and meet their health needs.

Global advocacy efforts are needed to build the evidence base for future worker health programs and promote implementation of FP/RH in worker health programming. 
porate policies to improve workplace practices (see "Advancing global and corporate policies and evidence-based workplace practices" below) and (2) two implementation science studies to assess the impact of workplace FP/RH programs on workers' health (see Figure 1, next page).

\section{Expanding the evidence base for worker health programming}

\section{Bangladesh}

The ready-made garment sector (RMG) accounts for approximately $11 \%$ of Bangladesh's gross domestic product and women account for $80 \%$ of the roughly 4 million workers employed by that industry. ${ }^{6}$ RMG has provided economic opportunities for many Bangladeshi women but working in this sector also brings increased health risks such as respiratory problems, joint pain, and anxiety. ${ }^{7-11}$ Many women working in Bangladesh's RMG sector are also in the earlier half of their reproductive years ${ }^{12}$ and have limited access to FP/RH services or menstrual hygiene products. In Dhaka division, there are three cities that account for the largest number of factories in Bangladesh. As of

\section{OUR IMPLEMENTATION SCIENCE APPROACH}

The Evidence Project used implementation science (IS)-the strategic generation, translation, and use of evidence-to strengthen, scale-up, and sustain voluntary family planning (FP) services.

Our IS approach was driven by collaboration with partners to: (1) define research priorities; (2) implement research activities; and (3) use evidence for decision-making.

This brief is part of a series of briefs synthesizing evidence and lessons learned through the project. Other briefs include:

- Expanding access to voluntary FP through private sector provision and self-administration of injectables

- Innovating and validating measures of complex concepts

These briefs and all other Evidence Project publications can be found at: http://evidenceproject.popcouncil.org/.

\section{ADVANCING GLOBAL AND CORPORATE POLICIES AND EVIDENCE-BASED WORKPLACE PRACTICES}

Advocacy efforts focused on improving the health of factory workers-beyond "occupational safety and health" to include FP/RHthrough improved data-driven policies and workplace practices within corporate supply chains.

Under the Evidence Project, the Meridian Group International used data to promote workers' health, including FP/RH, by recommending revised corporate policies, updated national guidelines, and new practical implementation tools. The project advanced global advocacy activities and worked at the national level in several low- and middle-income countries. Activities included-technical assistance for policy advocacy, publishing advocacy materials, dissemination of training manuals and materials for workplaces, and coordination of advocacy events. Examples of these global advocacy activities include the following:

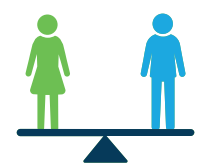

Provided key content on "Gender Equality in Codes of Conduct" guidance document for Business for Social Responsibility (BSR), a global nonprofit that supports the development of sustainable business strategies and solutions.

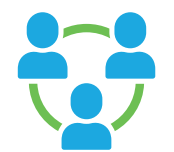

Supported the policy activities of 6 global standard-setting organizations providing technical assistance to these organizations to leverage their influence to elevate women's health.

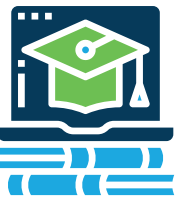

Developed and implemented a new professional development course on "Managing Health at the Workplace" for 24 factory mangers across 10 factories in Egypt. Supporty by the Levi Strauss Foundation, the course was used as a prototype for factories in its supply chain.

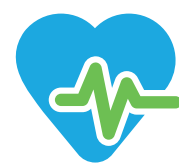

Promoted corporate action on Sustainable Development Goal 3 by improving the health and well-being of their employees through the United Nations Global Compact's "Health Means Business" Action Platform.

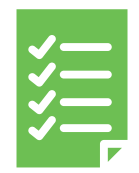

Published "Private sector action for women's health and empowerment: How business can invest in women and realize returns," featuring 8 actions companies can take to improve health outcomes for women.

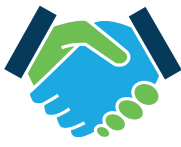

Obtained corporate commitments to improve workplace health activities, including a commitment from the Lotus factory to develop a FP clinic in the enterprise zone in Egypt. 


\section{FIGURE 1. STUDY IMPLEMENTATION SITES}

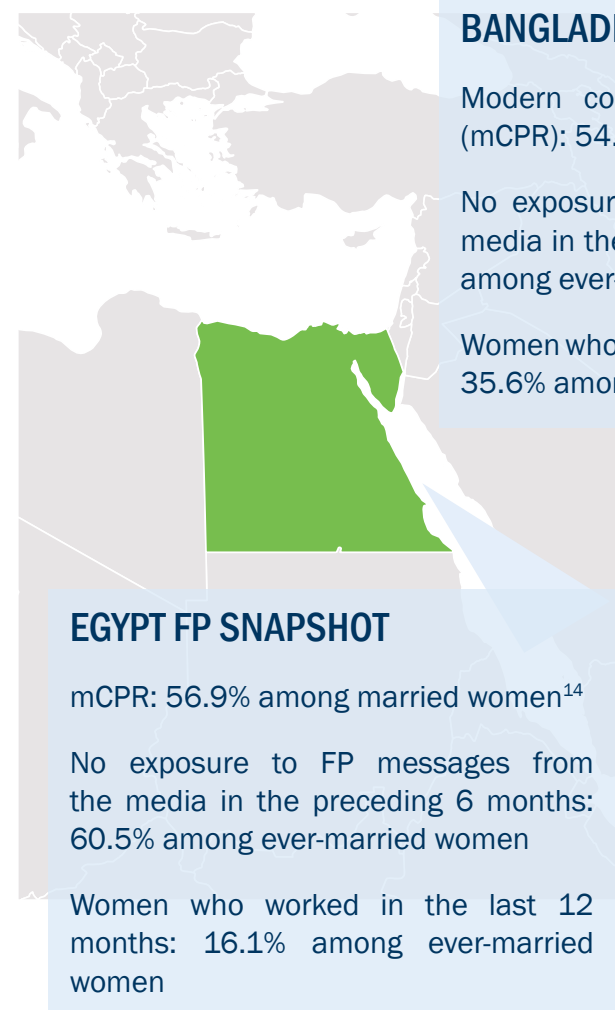

\section{STUDY OVERVIEW}

- Assessed the effect of integrating FP/RH into worker health programs to increase demand for and quality of private sector FP/RH services among male and female factory workers aged 18-35.

- Cross-sectional data were collected on FP/RH knowledge, attitudes, and practices from workers in intervention and comparison factories before and after the intervention.

- Qualitative data were collected from factory managers, peer educators, and factory workers after the intervention.
2018 , approximately $62 \%$ of married women of reproductive age in Dhaka division were using a FP method and $53 \%$ were using a modern method. ${ }^{13}$

Over the past decade, there have been increasing efforts to address the health, safety, and well-being of RMG workers in Bangladesh including some companies teaming up with non-profit organizations to deliver health messages and improved services. However, few workplace health programs with a focus on FP/RH have been evaluated.

\section{Egypt}

Egypt has seen a rise in its total fertility rate from 3.0 births per woman aged 15-49 to 3.5 between 2008 and 2014..$^{14,15}$ At the same time, the country saw a decline in exposure to FP messages from $70 \%$ to $49 \%$ among young people aged 18-35. ${ }^{14-16}$ These changes highlight the need for renewed attention to increasing awareness of and access to FP services among young people in Egypt.

Port Said is an urban governorate with a high mCPR equal to that of the country as a whole $-57 \%$ among married women age 15-49. It has an Investment Zone with 27 factories and 38,000 employees, of whom $60 \%$ are women, and $65 \%$ are between the ages of 18 and $35 .{ }^{17}$ Although Port Said has a high mCPR, more than half of the factory workers in the Investment Zone reside in neighboring governorates where access to $\mathrm{FP} / \mathrm{RH}$ information and services is lower than in Port Said overall.

\section{Evaluating models for worker health programming}

In Bangladesh, the Evidence Project evaluated the effectiveness of the HERhealth model for improving female factory workers' knowledge and behaviors surrounding FP/RH, which was implemented by BSR and Change Associates from 2015 to 2017 . The HERhealth model is a collaborative initiative that brings together global brands, their suppliers, and local nongovernmental organizations to deliver health information directly to female workers while strengthening the capacity of factory clinics to deliver expanded health services. In Bangladesh, HERhealth used peer health educators (PHEs) to disseminate health messaging related to FP, sexually transmitted infections (STIs), HIV/AIDS, nutrition, menstrual hygiene, early detection of breast and cervical cancer, and occupational health and safety through informal sessions during work 
hours. Depending on the factory size, between 24 and 80 female workers per factory were trained as PHEs. Each PHE disseminated messages for a specific topic for two to three months before moving onto the next topic. The HERhealth module was implemented for approximately 18 months in 10 factories in Dhaka, Gazipur, and Narayanganj districts. Most participating factories also strengthened the capacity of their onsite clinics by increasing stocks of contraceptives and feminine hygiene products. ${ }^{18}$

The objective of the intervention in Egypt was to increase demand for FP services among young people aged 18-35 in Port Said. Because of the large population of young people working in factories in Port Said, the target population was male and female factory workers in five garment factories in the Investment Zone. In collaboration with factory managers of the five included factories, the project selected 10-30 male and female workers from each factory to be trained as peer educators (PEs). One hundred eightysix PEs were trained, and each were assigned 40-45 factory workers with whom they were to share FP/RH messages and information through face-to-face interactions during bus rides and lunch breaks and via social and behavior change communication (SBCC) materials such as posters, fliers, and the Ma3looma social media websites. They referred workers who sought additional information about FP to the factory nurses who were trained in FP as part of the intervention. The intervention was implemented in partnership with the Port Fouad Childhood and Motherhood Association.

\section{Training materials}

In Bangladesh, the training curriculum for PHEs was based on the standard HERhealth curriculum developed by BSR, but the content was tailored to Bangladeshi women workers' needs. The final training curriculum included six core modules: (1) an introductory module including personal hygiene and waterborne diseases; (2) eating healthy; female body and menstruation; (3) maternal health and FP; (4) preventing STIs, HIV and AIDS; (5) malaria, dengue fever and reproductive cancers; and (6) occupational health and safety. PHEs were trained on these topics over the course of 10 weeks.

In Egypt, the Evidence Project developed training materials for the PEs as well as private sector physicians, pharmacists, and nurses. The PE materials covered general health topics, such as nutrition, personal hygiene, hazards of smoking and addiction, which a special focus on FP/RH, as well as interactive communication techniques. All private providers were trained on $\mathrm{FP} / \mathrm{RH}$ topics including available FP methods, potential method side effects, how to use each FP method, and myths and misconceptions about FP that are commonly held by young people in Egypt.

\section{On-site workplace peer education models, especially those augmented by social media and other communication materials, can address FP/RH needs of workers.}

The PHE model in Bangladesh improved workers' FP/RH knowledge and behaviors. Results from the evaluation of the HERhealth model found that training female factory workers as PHEs to deliver health messages while at work improved FP/RH knowledge and behaviors. As shown in Figure 2, factory workers' knowledge of the risk period for pregnancy during the menstrual cycle increased from $28 \%$ to $43 \%$ in the intervention factories and use of sanitary products increased from $23 \%$ to $72 \%$. There were no significant increases in the control factories. Figure 3 shows the proportion of ever-married women who re-

\section{FIGURE 2. PROPORTION OF FEMALE WORKERS WHO DEMONSTRATED SRH KNOWLEDGE AND BEHAVIORS}

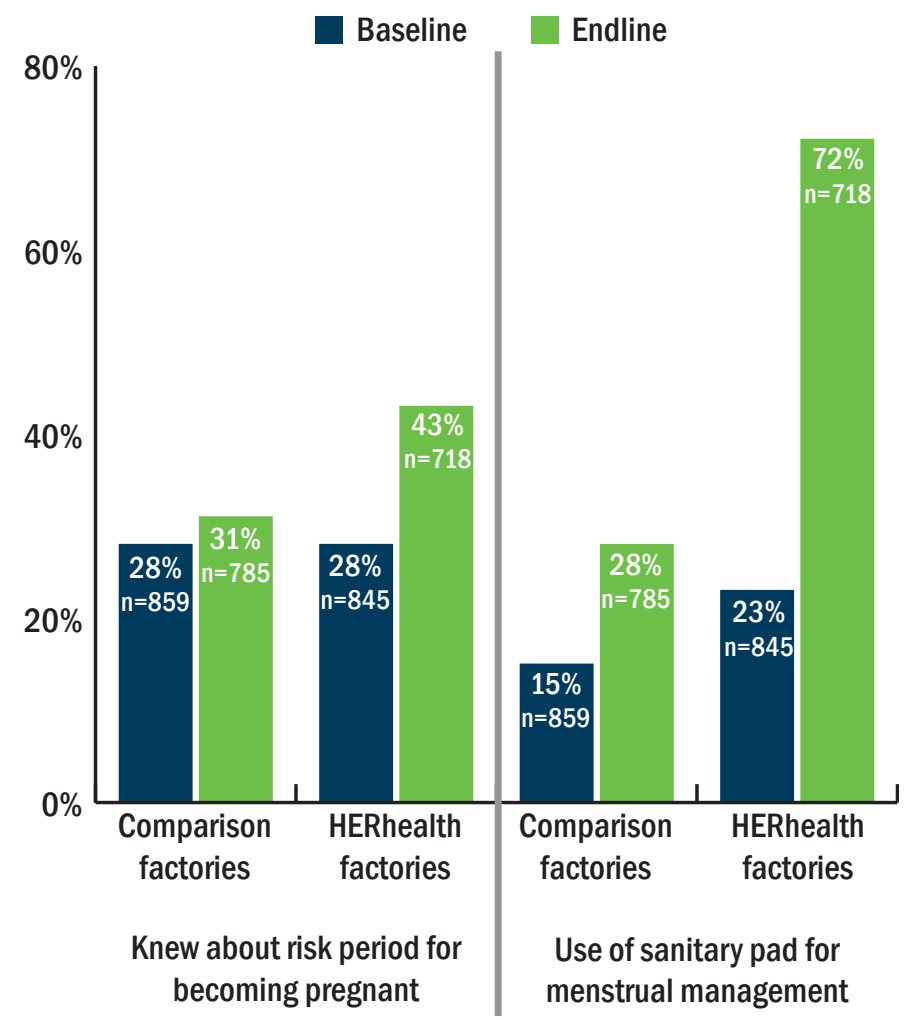




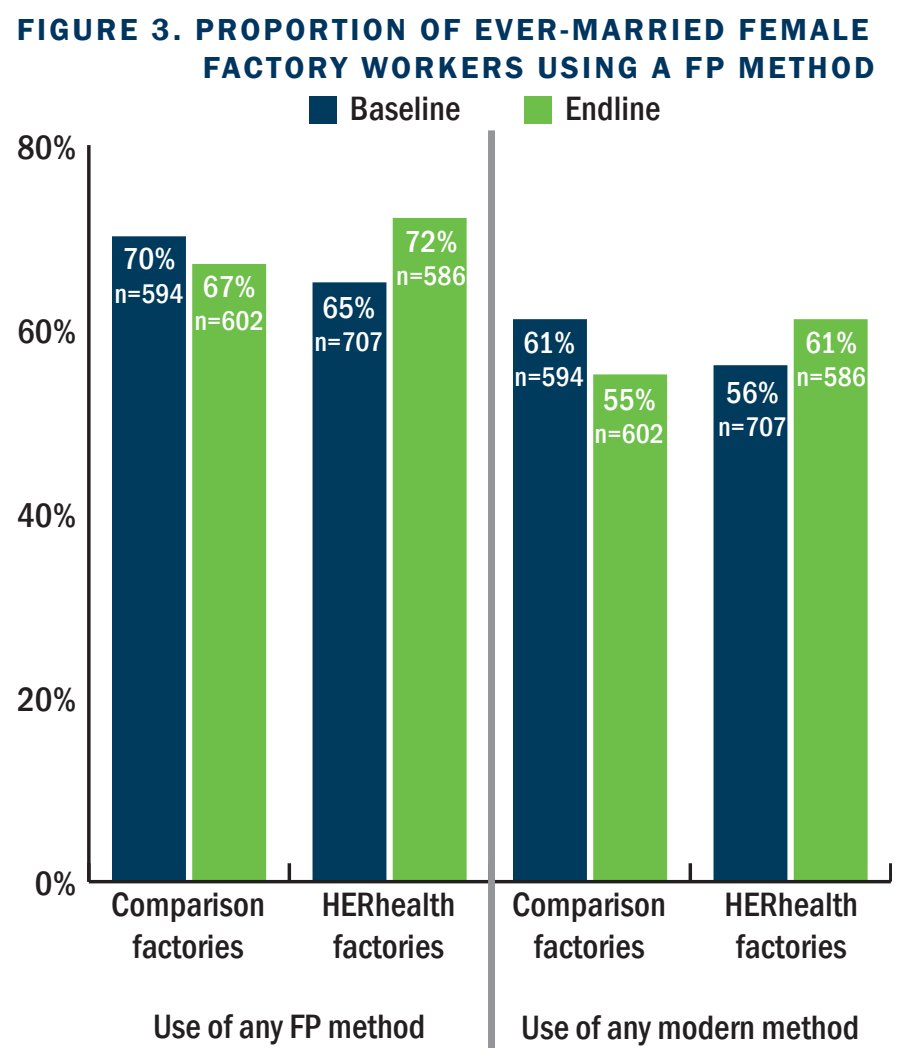

ported that they were currently using a FP method. There was no significant difference in the proportion of women reporting using any FP method in the comparison factories $(70 \%$ at baseline to $67 \%$ at endline) but the proportion increased significantly in the HERhealth factories $(65 \%$ to $72 \%$ ). Similar trends were observed for use of any modern method (data not shown). These encouraging findings in the intervention factories suggest that the PHE model should be expanded to more factories, and that longer exposures and repeated messaging could further strengthen the impact of the intervention.

The intervention in Egypt helped to identify barriers to successful implementation. Results from a the evaluation in Egypt showed that the intervention in Port Said had no measurable effect on FP/RH knowledge, attitudes, or behaviors among young men and women working in the factories. ${ }^{17}$ Although some indicators trended in the desired direction ( $41 \%$ of respondents disagreed that "FP methods can affect female fertility in the future" at baseline, and $44 \%$ disagreed at endline), no significant changes were found.

Several implementation issues were identified, including a high PE to worker ratio, time constraints limiting PEs' ability to convey messages, and high fees being charged by private trained providers. Additionally, factory workers frequently moved between factories and changed their mobile phone numbers, which made it hard to reach respondents for the intervention and to include them in the evaluation. ${ }^{17,19}$

Results from qualitative interviews with PEs, managers, and factory workers identified the approach as potentially promising for reaching young male and female workers, however some of the above-mentioned implementation issues were confirmed.

PEs in Egypt were seen as credible sources of information, with social media complementing in-person communication efforts. Qualitative findings demonstrated that over time, PEs became credible sources for information to their colleagues. However, it was noted that their work schedules limited opportunities for face-to-face interactions to share $\mathrm{FP} / \mathrm{RH}$ information with colleagues. To enhance communication, the Evidence Project used social media and SBCC materials to support PEs.

\section{6}

I used to meet regularly with my colleagues whenever we have some free time. For example, we can discuss the different topics when we are washing for prayers or when we sit to drink some tea. Whenever they are around, I begin discussing the topic with them.... Of course, I used to receive some silly jokes and unnecessary comments from my colleagues, but they began to understand as time passed. Afterwards, some people came to me when they had questions or have an issue with a certain FP method.... With time, people began to understand that peer educators are not silly, but s/he is a helpful person who delivers useful pieces of information that we can benefit from.

Male peer educator, 46 years old, Egypt

Despite the positive feedback about social media, it was noted that face-to-face communication remains a critical intervention component, as not all workers have access to social media.

In both Egypt and Bangladesh, PEs reported benefits from being involved in the projects, including knowledge gained and self-confidence. While PEs were not 
given financial compensation for their work, in both countries they reported benefits in terms of knowledge gained, serving as a trusted source of information among their peers, and self-confidence.

The Evidence Project also assessed knowledge retention of the PHEs in Bangladesh every two months for 12 months. After participating in the initial training, PHEs consistently scored highest for knowledge of two of the six modules: preventing STIs and HIV/AIDS and occupational safety and health. The results suggested that refresher trainings or other support mechanisms may be needed to ensure that PHEs maintain their knowledge after the initial training for all modules covered.

In Egypt, PEs felt that they had an important role in providing accurate $\mathrm{FP} / \mathrm{RH}$ information to their colleagues, especially given challenges with $\mathrm{FP} / \mathrm{RH}$ myths and misconceptions. They both benefitted from learning accurate information, and their self-confidence improved as they became trusted sources of information for colleagues, family members, and friends. PEs also reported increased self-confidence as well as improved communication and teamwork skills.

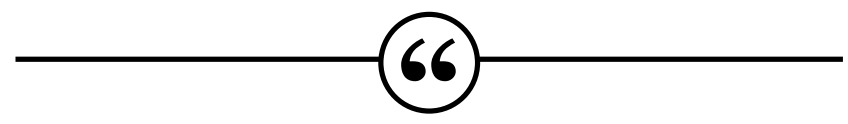

Honestly, we learned very useful information and a lot of beneficial stuff. We really benefited from the information in so many ways. It corrected several misconceptions that we already had. You know, what our parents teach us as well as the old customs and traditions. When we learned those pieces of information, we began to disseminate it to everyone.

Female peer educator, 35 years old, Egypt

\section{Collaboration with factory management can help to support successful implementation and generate interest in sustaining worker health programming.}

In both Egypt and Bangladesh, the involvement of factory management was integral to the successful implementation of the interventions. In Bangladesh, factory manag- ers nominated factory workers to act as PHEs, allowing the project to identify workers with strong leadership skills and facilitating a commitment to the project by the factory management. In-depth interviews conducted with factory management found that most managers viewed the intervention positively and believed that improved health of their workers would also help production. Some even suggested expanding the model to include content for male workers.

In Egypt, collaboration with factory managers from the outset ensured support for PEs to communicate health messages to employees and refer them to factory nurses as needed. This collaboration and enthusiasm also contributed to the sustainability of the project: a clinic was opened in the Investment Zone to serve factory workers onsite.

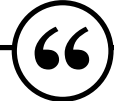

You see, it is really hard to disrupt the production line for half an hour due to the nature of work in the factory, so my role was to explain to the general manager and the middle management the benefits of this project to the workers and its positive impact on production as well. As long as the worker's health is good, he will be able to put in more effort and increase the total quantities produced.

Female manager, 38 years old, Egypt

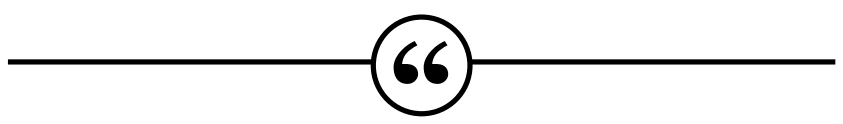

The idea of integrating family planning and general health into the factory was great. It made the workers feel that they are valuable because we, along with the nongovernmental organizations, valued their general health and well-being. It also enabled us to become trustworthy as the beneficiaries and peer educators got back to us whenever they had questions regarding the workers' general health. The project was very useful throughout the different phases.

Male manager, 37 years old, Egypt 


\section{PROMOTING RESEARCH USE IN EGYPT}

Learnings from this project led to the opening of the first Women's Health Clinic at the Port Said Free Investment Zone, funded by the Etisalat Foundation with support from the Investor's Association. This clinic is expected to serve a population of more than 20,000 female workers with subsidized FP services. This sustained interest will help to ensure the sustainability of the worker health intervention, and additional research can help to confirm the acceptability, feasibility, and effectiveness of this additional piece of the intervention.

\section{In addition to peer education,} making health services available on-site enables employees to overcome barriers and meet their health needs.

In Bangladesh, the HERhealth model had a significant positive effect on female factory workers' use of sanitary products for menstrual management. As part of the intervention, factory management worked with onsite clinics in the HERhealth factories to increase menstrual hygiene product availability. Greater changes in behavioral outcomes were observed when PHE messaging was coupled with activities that increased the capacity of factory clinics to provide services.

In Egypt, given that the goal of the project was to increase demand for and improve quality of private sector FP/RH services, workers who sought services were referred by the factory nurses to private providers trained by the project in FP/RH service provision. However, private providers in Port Said and neighboring governorates charge fees for their services, which one PE reported were too high for the workers to pay. Even though some providers nearby offered their services at a reduced rate to workers, some workers lived in neighboring governorates and took a factory bus home immediately after work, making it difficult to access services at the reduced rate. Providing services at a discounted rate on site would potentially further meet the FP/RH needs of factory workers.

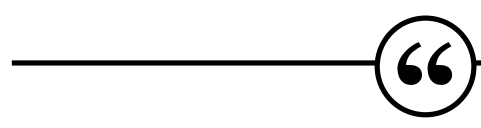

Honestly, some of these workers are hearing these health messages for the first time. Workers in the private sector cannot afford to go to private physicians. This is why this project is important.

Female peer educator, 35 years old, Egypt

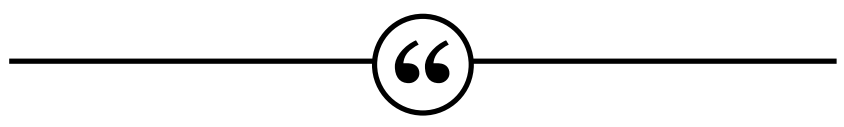

We have wanted a clinic here for a long time. The project made that happen. This will make a huge difference because many workers go to the nurse for counseling and when the nurse refers them to private physicians they can't afford to go. When we have a clinic in the Investment Zone with a qualified and trained physician, workers will benefit. This made the workers very happy.

Female peer educator, 30 years old, Egypt

\section{Ways forward}

In Bangladesh and Egypt, study results demonstrated the importance of continuing to build the evidence base and enhance interventions for worker health programs. In Bangladesh, the HERhealth model of using PHEs to disseminate health messages with colleagues at work was found to influence knowledge and behaviors, but fewer than $50 \%$ of women interviewed had correct knowledge for certain knowledge indicators. Identified areas for improvement include allowing sufficient time to share information in detail, expanding health content, increasing the frequency of messages, and continuing to increase the capacity of factory clinics. In Egypt, although the results of the quantitative study showed little effect of the intervention on knowledge, attitudes, and behaviors surrounding $\mathrm{FP} / \mathrm{RH},{ }^{19}$ results from qualitative interviews with PEs, managers, and workers demonstrated that this model of integrating FP/ RH into factories' worker health programs is a potentially promising approach for reaching young male and female workers.

Implementation science learnings suggest that intentional engagement of companies, and employees, throughout the 
research process is necessary to ensure effectiveness of the interventions. Ensuring sustainability remains a challenge, but collaboration with management and staff from the outset can support necessary buy-in, responsive research and program design, and enhanced implementation, which will lay the groundwork for lasting results. In addition, peer education models, especially those augmented by social media and other communication materials, may be valuable ways to meet women, men, and young people at work, but future research is needed on the optimal training and peer education models. Finally, to continue to meet the FP/RH needs of women and men where they are and to build the evidence base for future worker health programs, global advocacy efforts to promote implementation of and research on $\mathrm{FP} / \mathrm{RH}$ in worker health programming are paramount.

\section{References}

1. International Labour Organization. 2014. "Wages and working hours in the textiles, clothing, leather, and footwear industries." Geneva: International Labour Organization.

2. George, E. R., C. D. Gibson, R. Sewall, and D. Wofford. 2017. "Recognizing women's rights at work: Health and women workers in global supply chains," Berkeley Journal of International Law 35(1): 1-46.

3. United Nations. 2011. "Guiding principles on business and human rights." New York and Geneva: United Nations.

4. The Evidence Project. 2016. "Strengthening factory health systems under Levi Strauss \& Co.'s worker well-being initiative in Egypt," Brief. Washington, DC: Population Council, Evidence Project.

5. Wofford, D., S. MacDonald, and C. Rodehau 2016. "A call to action on women's health: putting corporate CSR standards for workplace health on the global health agenda," Globalization and Health 12:68.

6. Fathi, N. 2019. "Safety first: Bangladesh garment industry rebounds. international finance corporation.” World Bank Group.

7. Kabir, H, M. Maple, K. Usher, and Md S. Islam. 2019. "Health vulnerabilities of readymade garment workers: a systematic review," BMC Public Health 19:70.

8. Mahmud Md, S., D. Rajath, R. Mahmud, and N. Jahan Mst. 2018. "Health issues of female garment workers: Evidence from Bangladesh.” Journal of Population and Social Studies 26(3): 181-194.
9. Lillypet S, Jain T, Joseph B. 2017. Health problems among garment factory workers: A narrative literature review. JOHE, Spring 2017; 6(2).

10. Ahmed S, Islam N. 2014. "Physical and mental health of the workers in the readymade garment industry of Bangladesh," Pearl Journal of Management, Social Science and Humanities 1(1): 8-17.

11. Akhter S. et al. 2019. "Work, gender roles, and health: neglected mental health issues among female workers in the ready-made garment industry in Bangladesh," International Journal of Women's Health 9: 571-579.

12. SNV Netherlands Development Organization. 2016. "Baseline study of target garment RMG factories and their workers, 2015: Final report.” Dhaka: SNV.

13. National Institute of Population Research and Training (NIPORT), Mitra and Associates, and ICF International. 2016. Bangladesh Demographic and Health Survey 2014. Dhaka, Bangladesh, and Rockville, Maryland, USA: NIPORT, Mitra and Associates, and ICF International.

14. Ministry of Health and Population (MOHP), El-Zanaty and Associates, and ICF International. 2015. Egypt Demographic and Health Survey 2014 [Dataset]. EGIR61FL.DTA. Cairo, Egypt and Rockville, Maryland, USA: Ministry of Health and Population and ICF International [Producers]. ICF [Distributor].

15. El-Zanaty, Fatma and Ann Way. 2009. Egypt Demographic and Health Survey 2008 [Dataset]. EGIR5AFL.DTA

16. Abdel-Tawab, Nahla et al,. 2020a. "Fertility preferences and behaviors among younger cohorts in Egypt: Recent trends, correlates, and prospects for change." Cairo: The Evidence Project.

17. Abdel-Tawab, Nahla, Norhan Bader, Elizabeth Tobey, and Aparna Jain. 2020b. “Two implementation models of workers' health education programs in Egypt What works? What doesn't work?" Research Brief. Washington DC: Population Council, The Evidence Project.

18. Hossain, Md. Irfan, et al. 2017. "Evaluation of the effectiveness of the HERhealth model for improving sexual and reproductive health and rights knowledge and access of female garment factory workers in Bangladesh," Research Report. Washington, DC \& Dhaka, Bangladesh: Population Council, The Evidence Project.

19. Abdel-Tawab, Nahla et al. 2021 (forthcoming). Evaluation of two intervention models to integrate family planning into worker health and livelihood programs in Egypt: A difference-in-differences analysis. Accepted to Global Health Science and Practice.

This brief summarizes key findings from studies conducted by the Evidence Project/ Population Council teams led by Nahla Abdel-Tawab in Egypt, Md. Irfan Hossain in Bangladesh, and David Wofford of Meridian Group International in Washington, DC. These studies were conducted in collaboration with the Port Fouad Childhood and Motherhood Association and Baseera Center for Opinion Polls in Egypt, BSR and Change Associates Ltd. in Bangladesh, and Evidence Project staff in Washington D.C. Contributors to this brief were Sara Chace Dwyer, Michelle Hindin, Sherry Hutchinson, Aparna Jain, Leah Jarvis, Erika Martin, Katey Peck, and Elizabeth Tobey. We acknowledge the generous support of USAID Washington as well as the USAID Missions of Egypt and Bangladesh. We further acknowledge all the respondents who gave their time and provided valuable information during these studies.

\section{THE EVIDENCE PROJECT}

Population Council

4301 Connecticut Ave. NW

Suite 280

Washington, DC 20008

tel: +202 2379400

evidenceproject@popcouncil.org

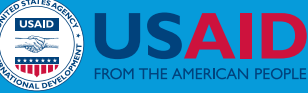

The Evidence Project is made possible by the generous support of the American people through the United States Agency for International Development (USAID) under the terms of cooperative agreement no. AID-OAA-A-13-00087. The contents of this document are the sole responsibility of the Evidence Project and Population Council and do not necessarily reflect the views of USAID or the United States Government.

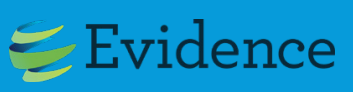

The Evidence Project uses implementation science-the strategic generation, translation, and use of evidence-to strengthen and scale up family planning and reproductive health programs to reduce unintended pregnancies worldwide. The Evidence Project is led by the Population Council.

Suggested Citation: The Evidence Project. 2021. “Meeting the family planning and reproductive health needs of factory workers," Learnings from the Evidence Project. Washington, DC: Population Council, The Evidence Project.

๑ 2021 The Population Council, Inc.

Photo credits: @ Evidence Project 